\title{
Baile, ruido y algarabía: un acercamiento a la interpretación de las "folías portuguesas"
}

Dance, noise and rejoicing: an approach to the performance of the Portuguese "folias"

\author{
(D) CRISTINA ROLDÁN FIDALGO \\ Universidad Autónoma de Madrid \\ cris.roldanfidalgo@gmail.com
}

\begin{abstract}
Resumen: Bajo el término "folía" han surgido a lo largo de la historia distintas manifestaciones literarias y musicales, lo que ha contribuido a la confusión que impera hoy sobre su significado. A finales del siglo XV y durante el siglo XVI, con el nombre de "folías portuguesas" se conocía a un espectáculo en el que la danza, el alboroto y el ruido parecen haber sido protagonistas, y cuyas características distintivas son aún poco conocidas. El presente trabajo tiene por objetivo arrojar luz sobre estas folías a través de relaciones de la época.
\end{abstract}

Palabras clave: folías portuguesas, danza, espectáculo, percusión, siglo XV.

Abstract: Throughout history, the term "folia" has been used to designate different literary and musical manifestations, which has contributed to the confusion that prevails today about its meaning. At the end of the $15^{\text {th }}$ century and during the $16^{\text {th }}$ century, the name "Portuguese folias" was used to refer to a performance in which dance, racket and noise seem to have been the protagonists, and whose distinctive characteristics are still little known. The present paper aims to shed light on these "folias" through contemporary sources.

Keywords: Portuguese folias, dance, performance, percussion, $15^{\text {th }}$ century.

Recibido: 2 de julio de 2020; aceptado: 15 de marzo de 2021; publicado: 31 de marzo de 2021.

Revista Historia Autónoma, 18 (2021), pp. 43-57

e-ISSN: 2254-8726; https://doi.org/10.15366/rha2021.18.002 


\section{A vueltas con la folía}

La ambigüedad del término "folía" — que ha adquirido numerosos significados a lo largo de su historia - ha dado lugar a distintas y variadas interpretaciones. Son numerosas las alusiones en fuentes históricas y literarias: desde crónicas portuguesas y españolas de los siglos XV y XVI que se refieren a las "folías" como un espectáculo secular ligado a Portugal, que aúna danza, canto y percusión ${ }^{1}$; hasta obras teatrales de autores como Gil Vicente (14651536?) y Sánchez de Badajoz (ca. 1525-1549) donde se alude a la "folía" como canción y como forma de interpretación propias de la tradición portuguesa ${ }^{2}$. Más conocidos son los testimonios musicales que, desde la primera aparición del término folía en De musica libri septem (1592) de Francisco Salinas, y a lo largo de los siglos XVI y XVII, la asocian a varias formas musicales, y que han sido objeto de numerosas investigaciones musicológicas ${ }^{3}$. En consecuencia, este rótulo ha servido para denominar tanto a una práctica festiva de tipo popular como a una danza estilizada con pasos codificados, a una forma poética ${ }^{4}$, a un tema musical y a una estructura armónico-melódica concreta, lo que ha llevado a que sea objeto de diferentes investigaciones por parte de musicólogos y filólogos.

Juan José Rey, tomando como punto de partida la definición de "folía" del Tesoro de la lengua castellana de Covarrubias (1611) — de la que se hablará después_-, explica su polisemia en los términos siguientes:

\footnotetext{
Básicamente, pues, la folía es una danza, con su música y su texto correspondientes y sazonada con un jolgorio rayano en la locura. Estos cuatro elementos (danza, música, texto y jolgorio) que en el hecho folklórico se dan inseparables, van a sufrir una evolución más o menos distante entre sí, conservando siempre cada uno el nombre que en principio solo se refería al conjunto. A ellos se añadirá otro elemento nuevo («un ostinato») que complicará más las cosas $[\ldots] .^{5}$
}

\footnotetext{
${ }^{1}$ Se encontrará un recorrido bastante completo por las distintas acepciones de "folía" (abordando, entre ellas, la folía como espectáculo festivo propio del siglo XVI y su conversión en una danza estilizada en el siglo XVII) en Esses, Maurice, Dance and Instrumental Diferencias in Spain During the 17th and Early 18th, New York, Pendragon Press, 1992, vol. I, pp. 646-647; pero también en Cacho, María Teresa, "La folía de España", en Profeti, Maria Grazia (ed.), Follia - Follie, Firenze, Alinea Editrice, 2006, pp. 73-100.

${ }^{2}$ Véase Weber de Kurlat, Frida, "Gil Vicente y Diego Sánchez de Badajoz. A propósito del Auto da Sebila Casandra y de la Farsa del juego de cañas", en Filología, 9 (1963), p. 161. Weber de Kurlat, Frida, "Acerca del portuguesismo de Diego Sánchez de Badajoz. Portugueses en farsas españolas del siglo XVI", en David Kossoff, Aron y José Amor y Vázquez (coords.), Homenaje a W. Fichter, Madrid, Castalia, 1971, pp. 785-800.

${ }^{3}$ Puede consultarse, entre otros: Griffiths, John, "Folía", en Diccionario de la música Española e hispanoamericana, coord. Emilio Casares Rodicio, Madrid, Sociedad General de Autores y Editores, 1999, pp. 182-185. Apro, Flávio, Folías de Espanha: o eterno retorno, Tese (doutorado em Música), Universidade de São Paulo, Escola de Communicação e Artes, Brazil, 2009. Fiorentino, Giuseppe, Folía. El origen de los esquemas armónicos entre tradición oral y transmisión escrita,. DeMusica 17, Kassel, Reichenberger, 2013.

${ }^{4}$ Juan José Rey fue el primero en estudiar la folía como forma poética a partir del Arte de la lengua castellana de 1625, escrito por Gonzalo Correas. Véase al respecto Rey, Juan José, Danzas cantadas en el renacimiento español, Madrid, Sociedad Española de Musicología, 1978, pp. 53-54.

${ }^{5}$ Rey, Juan José, Danzas cantadas... op. cit., p. 53.
} 
Algunos investigadores han tratado de establecer vínculos entre estas manifestaciones aparentemente tan distantes entre sí. El musicólogo Otto Gombosi planteó hace años esta problemática:

[...] algunos otros problemas sobre la Folia aún están esperando una solución. Es asombroso ver una danza portuguesa asociada con una melodía italiana; tal vez sea igual de asombroso ver una danza folclórica asociada con una melodía cortesana. La danza Folia, como la conocemos, y la melodía Folia, tal y como la conocemos, pertenecían a esferas culturales opuestas; y sin embargo, no cabe duda de que estuvieron juntas al menos a partir de mediados del siglo XVI [...] No podemos rechazar por completo la idea de que estas piezas de Folia sin la música de Folia representan una etapa anterior, cuando la melodía aún no estaba asociada con la danza y la danza podría tener cualquier música que se ajustara a su patrón rítmico y formal. La única dificultad es que estas extrañas composiciones de Folia sin melodías de Folia son bastante tardías. Pero, por otro lado, nunca podemos decir dónde y cómo sobrevive una vieja tradición. [...] Curiosamente, la Folia española de los siglos xvı y xvir muestra muy pocas afinidades con la Folia portuguesa desde el punto de vista coreográfico. Parece que la melodía se asoció primero con la danza portuguesa y luego fue asumida por los españoles, quienes la designaron con el nombre de la danza portuguesa, pero la usaron para otra forma de danza perteneciente al tipo Gallarda. ${ }^{6}$

Sin embargo, la contaminación de significados sigue imperando hoy. No será el propósito del presente trabajo tratar de arrojar luz sobre esta problemática, sino atender particularmente a esas primitivas "folías" de origen portugués, a las que solo parece posible acercarse mediante relaciones históricas de los siglos XV y XVI. Estas "folías portuguesas" habrían sido un tipo de práctica festiva y popular caracterizada por su forma de interpretación, y no habrían estado aún vinculadas con la melodía a la que se asociaría el término después y que se convertiría en uno de los temas musicales europeos más antiguos y conocidos ${ }^{7}$. Curt Sachs las considera como una danza de fertilidad ligada al Carnaval, que no tenía pasos reglados y cuya música terminó siendo más conocida que la danza en sí misma ${ }^{8}$. José Sasportes y Antonio Pinto Ribeiro las sitúan en el reinado de D. Juan II de Portugal (1481-1495) como una danza de conjunto de tipo procesional, en sintonía con otras manifestaciones similares organizadas en las cortes europeas ${ }^{9}$. El objetivo del presente trabajo será, a través de la información que nos aporta esta tipología de fuentes, caracterizar esta práctica festiva.

\footnotetext{
${ }^{6}$ Traducción propia a partir de Gombosi, Otto, “The cultural and folkloristic background of the Folia”, en Papers of the American Musicological Society, 1 (1948), pp. 89-90.

${ }^{7}$ Gombosi, Otto, "The cultural and folkloristic... op. cit.

${ }^{8}$ Sachs, Curt, World History of the Dance, New York, W.W. Norton \& Company Inc., 1937, p. 413.

${ }_{9}^{9}$ Sasportes, José y António Pinto Ribeiro, História da dança em Portugal, Portugal, Imprensa Nacional Cada da Moeda, 1991, p. 13.
} 
2. ¿Qué eran las folías portuguesas?

La primera definición la proporciona Sebastián de Covarrubias en el Tesoro de la lengua castellana o española (1611):

Es una cierta danza portuguesa, de mucho ruido; porque ultra de ir muchas figuras a pie con sonajas y otros instrumentos, llevan unos ganapanes ${ }^{10}$ disfrazados sobre sus hombros unos muchachos vestidos de doncellas, que con las mangas de punta van haciendo tornos, $\mathrm{y}$ a veces bailan. $\mathrm{Y}$ también tañen sus sonajas, y es tan grande el ruido, y el son tan apresurado, que parecen estar los unos y los otros fuera de juicio: y así le dieron a la danza el nombre de folía de la palabra toscana folle que vale vano, loco, sin seso, que tiene la cabeza vana.

Bien lo sabía el lexicógrafo, pues fue precisamente su padre, el historiador Sebastián de Horozco, quien dio cuenta en sus Relaciones históricas toledanas de unas "folías" que formaron parte de las fiestas dispuestas en Toledo en 1560, con ocasión del matrimonio de Felipe II con Isabel de Valois y de su visita a la ciudad. Su descripción coincide con la proporcionada por el Tesoro:

Salieron de Toledo cuatro carros triunfales, cada uno de cuatro ruedas como coches, muy lindamente hechos y pintados al romano, con muchas aves y pinturas de muchas maneras a lo antiguo como se pintan en los triunfos. Y las mulas que los tiraban iban muy encubertadas de telillas de diversos colores y enramadas, que no parecían ser mulas sino otros animales. En uno de estos carros iba mucha música de ministriles. Y ciertos niños que cantaban muchos villancicos y coplas a propósito de la venida de la reina para paz de la cristiandad. Tras este carro salió una danza de folías, que eran unos muchachos muy bien ataviados de mujeres de diversos colores de tafetanes y rasos tocados muy ricamente y con sus guirnaldas de yedra como ninfas. A éstos llevaban sobre los hombros unos hombres grandes con un artificio de palos, por manera que las folías iban sentadas sobre sus hombros como en sillas. Y los hombres que las llevaban iban también muy bien vestidos de lo mismo, que serían todos veinticuatro. $Y$ éstos iban bailando y las folías cantando canciones al propósito y tañendo con unas sonajas en las manos y panderos, cosa muy graciosa y de ver. ${ }^{11}$

Parece que en el testimonio citado, Horozco emplea "folías" para referirse a los participantes de la danza; sin embargo, en las relaciones coetáneas no suele encontrarse el

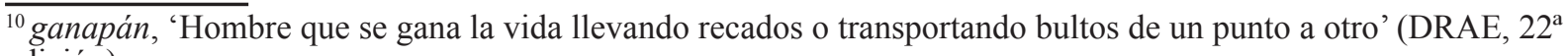
edición).

${ }^{11}$ Horozco, Sebastián de, Relaciones históricas toledanas, Toledo, I.P.I.E.T., 1981, fols. 230-249.
} 
término asociado a los integrantes de la danza, sino a la danza en sí misma. Veamos algunos ejemplos.

En torno al año 1525 el reverendo portugués Fray Francisco de Valdeolivença predicó en Lisboa, en Nuestra Señora de Gracia, un sermón con motivo de la conmemoración de la victoria del rey Juan contra Castilla, cerca de Aljubarrota. En el mismo da cuenta de que, a finales de 1524, el pueblo de Yelbes (Badajoz) recibió a la reina de Castilla con una danza llamada "folía":

Acaeció en Yelbes en fin del año de 1524, entrante el de 25, que acompañando a la Serenísima Reina de Castilla Doña Catalina, Don Álvaro de Zúñiga, Duque de Béjar, y su yerno Don Francisco de Sotomayor, Marqués de Ayamonte y Conde de Benalcázar, con toda la caballería extremeña, los de Yelbes la recibieron, a la verdad, con mucha gente del reino, pero sacaron una danza que ellos llaman folía, la cual guiaba un tejedor que para ello trajeron de un lugar llamado Arronches, el cual, a vueltas de la danza o folía, levantó un cantar que decía: "Ela se vino, ela, / que ningun não fo por ela". ${ }^{12}$

De la descripción se infiere que esta folía era una danza callejera, guiada en este caso por un artesano portugués (un aficionado, por tanto) y que, mientras se ejecutaba, se cantaba un tono que no se ha conseguido localizar. En el resto de relaciones localizadas se suele hablar no de una "danza de folía", sino con mayor frecuencia de "danzas y folías" o de "bailes y folías". Estos términos son acuñados en varias ocasiones por el portugués García de Resende en su crónica del reinado de D. Juan II de Portugal (1481-1495), a finales, por tanto, del siglo XV. Al hablar de un sarao que tuvo lugar en Terreiro do Paço (terreno donde se asentaba el Palacio Real de Lisboa) y por las calles principales de la ciudad, refería lo siguiente:

[...] hubo un gran sarao de muchas danzas, bailes, alegrías y fiestas. Toda la gente de la ciudad participó en danzas y folías con enormes antorchas en la plaza Terreiro do Paço, y por todas las calles principales, tantas personas honorables y nobles, así como del pueblo, que no cabían, nunca vi tanto alboroto y alegría. $Y$ muchos ancianos y ancianas movidos por el placer fueron juntos a cantar y bailar delante del rey y la reina: sus edades les excusaban. ${ }^{13}$

A juzgar por el citado testimonio, las folías no parecen haber sido una danza como tal, sino un espectáculo que podía convivir con la danza y en el que parece haber participado tanto gente

\footnotetext{
${ }^{12}$ Diego Hurtado de Mendoza, "Sermón hecho en Lisboa por Fray Francisco de Villadolencia, portugués en Nuestra Señora de Gracia, vigilia de la Asunción, celebrando una vitoria que los portugueses hubieron de los españoles tal día como éste en Aljubarrota, lugar del Rey de Portugal”. en Sales españolas o agudezas del ingenio nacional, Antonio Paz y Meliá, Madrid, Impresor de Cámara de Su Majestad, 1890, pp. 186-187.

${ }^{13}$ Resende, García de, Vida e feitos d'el-rey Dom João II, Ed. Evelina Verdelho, Coimbra, Universidad de Coimbra, 2007, p. 150. Traducción propia del original: "E toda a gente da cidade foi posta com muita brevidade em danças e folias, com infindas tochas na praça e no Terreiro dos Paços, e por todas as ruas principaes, e tanta gente honrada e nobre, e assi a do povo, que não cabia, nem se viu nunca tanto alvoroço e alegria, e muitos velhos e velhas honradas com sobejo prazer foram juntos cantar e bailar diante de El-Rei e a Rainha, cousa de que suas edades os bem escusavam".
} 
humilde como noble. Se alude nuevamente al "alboroto" que producían — como se afirmara asimismo en el Tesoro de la lengua-.

Otras relaciones prestan atención al aspecto cantado de las folías, sin perder de vista que su ejecución a menudo se acompañaba de bailes. En 1581 Gaspar de los Arcos escribía una carta a Pedro Morlanes (criado de Su Majestad Felipe II) desde la ciudad portuguesa de Tomar, donde afirmaba que las folías eran cantadas y resultaban incomprensibles para los españoles, precisamente por el alboroto antes mencionado:

En lo que Vuestra Merced me manda que le diga del recibimiento de Abrantes, ya en la otra carta hago mención de él y de todos los otros, porque son de una mejora manera todos, con muchas folías, y muchas danzas de muchas maneras, que es esto lo que más se usa en Portugal, y cantan tan alto que los pueden oír de una legua, y si hay dos docenas de portugueses todos cantan juntos a la revuelta, pero aunque V. M. esté todo el día muy atento a lo que cantan, no les entenderá palabra de la misma manera al predicador que aunque es uno solo, no hay entenderle la palabra, y así todos estamos como si estuviésemos en Turquía. ${ }^{14}$

Se desconoce cómo sería la música de estas canciones, y si valdría cualquier tono para acompañar a las folías, o si se contaba con un repertorio específico. En todo caso, estos cantos parecen haber sido acompañados de instrumentos, sobre todo de percusión. Al respecto resulta interesante traer a colación el relato de Giovanni Battista Venturino del viaje del enviado del papa Pío V, el cardenal Alexandrino, a España y Portugal (1571), donde pudo escuchar (y ver) una folía: "La folía era de ocho hombres vestidos a la portuguesa, que con platillos y panderetas afinados por igual, golpeando sonajas atadas a sus pies, celebraban alrededor de un tambor, cantando en su idioma versos de alegría"15.

También es sabido que en 1564, en el Alcázar de Madrid, como parte de una mascarada dispuesta por las damas de la princesa Juana y de la por entonces reina Isabel de Valois (tercera consorte de Felipe II) se cantaron y tañeron unas folías:

Para la máscara, las damas se distribuyeron en dos bandos. La Reina y siete damas de una parte, y la Princesa y otras tantas de la otra: "el precio fue un escritorio que valía mil y quinientos ducados, por parte de la Reina; y la princesa puso una arquita, que costó dos mil quinientos, llena de guantes, gorgueras y lienzos, de cadenetas y muchos perfumes...”. Cada cuadrilla, con disfraces, máscaras, músicas, bailes y en ocasiones escenografía, representaba, en diferentes cámaras, una invención. La princesa tenía que adivinar quién de entre las damas disfrazadas y enmascaradas era la reina, y asimismo la reina con la cuadrilla de la princesa.

\footnotetext{
${ }^{14}$ Cartas de Gaspar de los Arcos a Pedro Morlanes, criado de Su Majestad, Biblioteca Nacional de España (en adelante BNE), MSS/20209/27.

${ }^{15}$ Traducción propia a partir de Resende, García de, Chronica de 'L Rei D. João II, Bibliotheca de Classicos Portuguezes, Lisboa, 1902, p. 64.
} 


\section{LA PRINCESA}

Sacó la primera invención de esta manera: ocho portugueses, comendadores de la Orden de Cristo, muy bien aderezados con caperuzas y birretes y puntas de oro; estaban debajo de unas cortinas y un cielo de tela de plata carmesí cuatro damas y cuatro mozas de cámara, vestidas a la portuguesa y con cántaras en la cabeza llenas de flores, y en entrando la reina y sus damas comenzaron a tañer y cantar folías portuguesas, y andaban por junto las del juego, que parecía muy bien. No acertó la Reina [...]. ${ }^{16}$

Por lo tanto, parece que las folías de los siglos XV y XVI eran un tipo de espectáculo cuyo "hábitat natural" fueron las calles y plazas portuguesas —aunque por la última relación mencionada se comprueba que podían interpretarse también en las cámaras de palacio-. En ellas participaba un gran número de personas de muy distinta clase, que bailaban, cantaban, y tocaban instrumentos de percusión probablemente todas a la vez y produciendo el mayor ruido posible. Esta algarabía podía ser "ordenada" o "dirigida" por alguno de los participantes de la folía. En las relaciones conservadas, las folías se interpretan ante la realeza, aunque pudieron haber servido de entretenimiento en otras ocasiones menos señaladas que no hubieran dejado un rastro documental.

Estas folías parecen haber continuado en la centuria posterior, aunque en este siglo cada vez encontramos más testimonios que asocian la palabra "folía" a la música (la que fuera la "early folia" o "folía temprana" según la clasificación de Richard Hudson ${ }^{17}$ ) y no aluden a ella como el espectáculo ruidoso y callejero anteriormente descrito. Esto probablemente se deba también a que, como señalara Maurice Esses, ya desde inicios del siglo XVII el término "folía" pasa a corresponder a una danza aristocrática de pasos codificados ${ }^{18}$. Sirva de ejemplo de uno de estos últimos testimonios la Relación de la real tragicomedia con que los padres de la Compaña de Jesús en su colegio de S. Antón de Lisboa recibieron a la Majestad Católica de Felipe II de Portugal, y de su entrada en este Reino, con lo que se hizo en las Villas y Ciudades en que entró (1620):

Entra el Rey don Manuel alegre con la buena nueva de la llegada de Vasco de Gama, de que ya tenía aviso. Lisboa envuelta en cordial contento, acompañada de su Tajo y Cintra [sic.] se viene a ofrecer al Rey, para celebrar la alegre y venturosa llegada de los fuertes Argonautas Portugueses Indianos: y porque el Tajo con las danzas de sus pastores había festejado su partida, la verde Cintra [sic.] toma a su cuenta, y se encarga de celebrar su alegre llegada, con folias de sus músicos serranos, y luego le van a buscar $[\ldots]$

\footnotetext{
${ }^{16}$ González de Amézcua y Mayo, Agustín, Isabel de Valois, reina de España (1546-1568). Estudio biográfico, Madrid, Gráficas Ultra, 1949, vol. III, pp. 468-72. Cit. en Ferrer Valls, Teresa, La práctica escénica cortesana: de la época del Emperador a la de Felipe III, London, Tamesis Books, 1991, pp. 35-36.

${ }^{17}$ Hudson, Richard, "The Folia dance and Folia formula in 17th Century Guitar Music", Musica Disciplina, 25 (1971), pp. 119-221.

${ }^{18}$ Esses, Maurice, Dance and Instrumental... op. cit., p. 646.
} 
Folia

Constaba la folia de nueve gallardos mozos pequeñuelos vestidos de varios colores, marlotas, jubones, y grigescos [sic.] de tela y raso de oro bien guarnecidas de pasamanos de lo mismo, medias de seda con hermosas ligas de puntas de oro, las mismas en las cintas y cabezas con que ceñía unos grandes turbantes de raso colorado, de guarniciones de oro, zapatos blancos, venía entre ellos un lindo muchacho con su tambor, y los demás con sus cetros y sonajas, cantaban a la campones [sic.] alternados al son siguiente una letrilla portuguesa $[\ldots]^{19}$.

\section{Los participantes de las folías: los "folliães" o foliones}

Al estudiar las anteriores relaciones se ha aludido indirectamente a los participantes de las folías, pudiendo comprobar que eran quienes caracterizaban y daban sentido a este espectáculo. $\mathrm{Su}$ vestimenta y su interpretación musical (baile, canto y percusión) son los elementos que identifican a las folías, las cuales no solo "se escuchaban", sino que sobre todo "se veían". Merecen, por tanto, un epígrafe aparte, con el fin de caracterizar estas figuras.

García de Resende, en su crónica ya mencionada del reinado de D. Juan II de Portugal, refiere el recibimiento en Évora a la princesa Isabel el 27 de noviembre de 1490. En la relación habla de la ejecución de folías e introduce el término "folliães": "Y del monasterio a la ciudad hubo muchos entremeses [...] con muchas folias de foliães y muchachas muy bien vestidos" 20 . Consultando uno de los diccionarios contemporáneos de la lengua portuguesa, el Dicionário Priberam, es posible comprobar que efectivamente se recoge el término "Folião", que deriva de "Folia", y que se refiere a "quien participa en las folías" o a "quien tiene como función divertir a otros danzando o representando". Aunque en la relación de Horozco parecía que "folías" hacía referencia tanto a la danza como a quienes intervenían en ella, a la vista de la crónica de García de Resende se entiende que existió además un término para denominar específicamente a sus participantes.

En base a su testimonio, "folliães" habrían sido personas caracterizadas o disfrazadas de una determinada manera, de forma que dejaban de ser simples hombres o mujeres para convertirse en los participantes de las folías. Se distinguen así de las "mozas" que intervinieron

\footnotetext{
${ }^{19}$ Relación de la real tragicomedia con que los padres de la Compaña de Jesús en su colegio de S. Antón de Lisboa recibieron a la Majestad Católica de Felipe II de Portugal, y de su entrada en este Reino, con lo que se hizo en las Villas y Ciudades en que entró. Recogido todo verdaderamente y dedicado al Excelentísimo señor Don Theodosio segundo, duque de Braganza \&c. Por Juan Sardina Mimoso, sacerdote, natural de Setubal, Lisboa, Impreso por Jorge Rodríguez, 1620, 48v.-49r.

${ }^{20}$ Traducción propia a partir de García de Resende, Vida e feitos... op. cit., p. 167.
} 
también en la fiesta, pero se dice tanto de ellos como de ellas que iban "muy bien vestidos". Similar alusión a la riqueza del vestuario realizaba García de Resende en otro párrafo de su crónica. Con motivo de la llegada de los reyes a Santarém (Portugal), hubo, entre otros festejos, "muchas folías de hombres y mujeres muy bien vestidos con los colores de la princesa" 21 , de lo que se deduce que el vestuario de quienes ejecutaban las folías resultaba de suma importancia para su caracterización.

En Madrid, en la plaza del Real Palacio, también hicieron su aparición los “folliães”, cuyo nombre aquí se habría traducido como "foliones". En una sortija que se hizo el 31 de marzo de 1590 - y en la que participó, entre otros, Felipe II — Pedro de Guzmán dispuso una "invención" en la que participaban diversas figuras y, entre ellas, hubo "muchos foliones a lo portugués":

\begin{abstract}
Empezóse la fiesta a las dos de la tarde y duró hasta la noche: y a un lado de la sortija, una campanilla que la había de tañer el que echaba la lanza por encima, y al otro lado un estafermo. Fue mantenedor el conde de Melgar, y por su ayuda Don Juan de Sandoval, vestidos de encarnado, paro y plata; sacaron cuatro tambores, ocho trompetas, doce lacayos y los pajes en muy buenos caballos enjaezados y ocho padrinos y cuatro herradores, todos de su librea; entraron con sus herramientas doradas en las manos, las cubiertas muy galanas, con mucho oro y bordaduras [...] Don Pedro de Guzmán, hermano del conde de Olivares, sacó por invención una boda con muchos foliones a lo portugués, seis padrinos, y él vestido de negro y encarnado y oro y plata, y encima un capuz largo de terciopelo, bordado con muchos espejos. Letra "De otros vejo os venís á qui: Os males se veem em mí". Diéronle el precio de mejor letra; corrió con el conde y ganó el precio $[\ldots]^{22}$
\end{abstract}

De ello se desprende que los foliones iban vestidos con un atuendo característico que les identificaba, y que éste se vinculaba a Portugal en el imaginario colectivo. Acaso en la "boda" que se dispuso, los foliones pudieran haber interpretado folías, pues la danza estuvo bastante presente en esta sortija. Así, por ejemplo, en una invención de Don Pedro de Toledo se hizo una "danza de negros", otra de "aldeanas con capillos", otra "de sayagüeses con una novia negra", etc.

De la faceta de músicos de los "folliães" o "foliones" parece dar cuenta Alonso de Santa Cruz, cosmógrafo del monarca Carlos V, en la denominada Crónica del Emperador Carlos $V$. Durante la llegada de la armada que enviaba el rey Juan de Portugal a Carlos V el 28 de abril de 1535, “[...] cada Capitán en su batel con sus banderas vino al galeón donde venía su Capitán mayor, con el cual vinieron a tierra con muy buena orden, con muchas chirimías y sacabuches y trompetas y foliones [...]"23. Es evidente que los términos "chirimías", "sacabuches" y

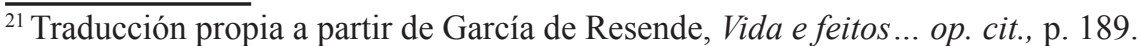

22 "[Relación de la sortija que se hizo en 31 de marzo de 1590]", en Simón Díaz, José (ed.), Relaciones de actos públicos celebrados en Madrid (1541-1659), Madrid, Instituto de Estudios Madrileños, 1982, p. 35.

${ }^{23}$ Santa Cruz, Alonso de, "Cómo vino a Barcelona una armada que el Rey de Portugal envió al Emperador, y la armada de las galeras del Príncipe Andrea Doria, y la que trajo de Málaga el Marqués de Mondéjar, con la que
} 
"trompetas" se emplean aquí para denominar no a los instrumentos, sino a los músicos que los portaban; probablemente los "foliones" serían también músicos que llevaban tal variedad de instrumentos que era suficiente con el vocablo "foliones" para identificarlos, lo que no excluye que también la danza pudiera haber sido uno de sus cometidos. Acaso entre sus instrumentos estuvieran los címbalos, tambores y sonajas a los que hacía alusión el italiano Giovanni Battista Venturino en la crónica ya citada.

El propio rey Felipe II hablaba de la ausencia de "foliones" para referirse a la ausencia de folías en una carta dirigida a sus hijas, las infantas Isabel Clara Eugenia y Catalina Micaela, y escrita en Lisboa el 25 de junio de 1582. De ello se desprende que la presencia de estas figuras en la folía era imprescindible o, al menos, si no se decía lo contrario se daba por supuesta:

\begin{abstract}
Muy bien ha sido ir a la del Campo y ya creo que estaréis en las Descalzas y de allí más lejos os caerá. Y también lo fue ver las danzas de Corpus Christi. Y si vuestro hermano tiene miedo de aquellas cosas, procurad que no le tenga y decidle de lo que son, que con esto lo perderá. Acá no hubo foliones, sino muchas danzas de mujeres y algunas que cantaban bien, aunque, como os escribí, yo pude ver poco, por ir al cabo de la procesión y ser tan larga. ${ }^{24}$
\end{abstract}

Adviértase que el monarca daba cuenta de unas danzas de mujeres, destacando que "algunas cantaban bien", lo que indica que las danzas en esta época iban ligadas al canto hasta el punto de que éste constituía un aspecto a valorar. De ser así, acaso la falta de mención a que las folías eran danzadas se debiera a que se daba por hecho.

A pesar de la existencia de los términos "folliães" o "foliones", parece que en ocasiones se emplea el de "folías" para denominar a estas figuras y a las danzas que ejecutan. En 1543, con motivo de las primeras nupcias del rey Felipe II con doña María Manuela de Portugal (hija de Juan III y de Catalina de Austria), se celebraron diversas fiestas en tierras españolas para recibir a la princesa, y en dos de ellas hubo folías. Así lo afirma una crónica que escribe una mano anónima al Emperador Carlos V - que al no poder asistir personalmente a la boda, le pide a éste que se la relate - acerca del viaje a Alcántara (Cáceres) de la futura reina:

El martes siguiente, partió de aquí y fue a dormir a Alcántara, hízosele recibimiento al modo y posibilidad de la tierra con mucha gente de a caballo en buena cantidad y gran estruendo de mozos que cantaban y folias que es lo que más por allí se usa por ser raya de Portugal y lo que entonces más agradaba a su Alteza y regocijaba a las damas por parecerles que aún no habían salido de su tierra. No pongo aquí las antiguallas de la puente porque ya las dice al por sí. ${ }^{25}$

\footnotetext{
salió de Vizcaya, todas muy proveídas de gente de guerra y artillería”, en Beltrán y Rózpide, Ricardo, Crónica del Emperador Carlos V, [S.1.] : [s.n.], 1920-1925, p. 255.

${ }^{24}$ Bouza, Fernando (ed.), Cartas de Felipe II a sus hijas, Madrid, Akal, 1998, p. 87.

${ }^{25}$ Papeles históricos de los siglos XVI y XVII, BNE MSS/4013.
} 
De la cita se desprende que hubo mozos que cantaban y que a su vez hubo "folías", que acaso eran de nuevo figuras disfrazadas de una manera determinada y provistas de instrumentos musicales para provocar un "gran estruendo".

Más tarde, en una carta fechada el 17 de septiembre de ese mismo año, y en la misma ciudad, Felipe II de nuevo refiere a su familia la interpretación de folías:

Y Magdalena [la enanita Magdalena Ruiz, llamada "la loca", y criada de las Infantas ${ }^{26}$ ] tiene un pedazo de un terradillo que sale a la plaza en su aposento y ha estado tan ocupada en componerle que no ha podido escribir, ni aun creo que ha querido, aunque yo se lo he acordado algunas veces, que dice que no puede acabar consigo de escribir en vísperas de toros; y está tan regocijada para ellos como si hubiesen de ser muy buenos y creo que serán muy ruines.

Lo mejor creo que serán folías que dicen que han de andar por la plaza. ${ }^{27}$

Esta observación resalta el espíritu urbano de las folías, que "andan por la plaza”, y pudiera recordar a esas comitivas de locos de la Edad Media que iban por las calles llenándolas de ruido, música y fiesta. Por lo tanto, parece reforzar la idea de que las folías no eran necesariamente unas danzas codificadas, sino una especie de fiesta con gran protagonismo del baile y el canto, donde imperaba el desorden y el ruido, y donde, a juzgar por las relaciones precedentes, participaban gentes de toda condición y en gran número, los foliones, "folliães" o "folías", que recibían estos nombres por su disfraz y por los instrumentos que portaban (la mayoría de percusión).

\section{Referencias a folías y foliones en obras teatrales}

Más conocidas que las anteriores relaciones históricas, son las menciones a las folías en las obras del dramaturgo portugués Gil Vicente (1465-1536?) y del español Sánchez de Badajoz (ca.1525-1549), que en algunas ocasiones encajan con las características ya descritas. Gil Vicente empleó el término "folía" al menos en cinco ocasiones dentro de su obra: para dos canciones pedía a los intérpretes que las arreglaran ellos mismos "em folia" (Templo d'Apolo, y Auto da feira); para una tercera canción los intérpretes eran vestidos "em folia" (Triunfo do inverno); en una cuarta les pedía que lo cantaran "de folia" (Auto da Sibila Cassandra); y en otra ocasión más un personaje refiere una canción como una "folia" $(O \text { velho da horta })^{28}$. Como puede comprobarse, la polisemia del término a la que aludíamos al inicio de este trabajo se encuentra asimismo representada en este repertorio.

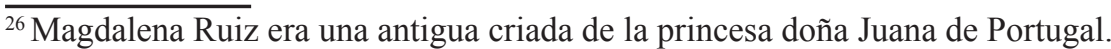

${ }^{27}$ Bouza, Fernando (ed.), Cartas... op. cit., p. 91.

${ }^{28}$ Esses, Maurice, Dance and Instrumental... op. cit., p. 643.
} 
También en estas obras se hace mención en ocasiones a los participantes de las folías o foliones. Al respecto cabe destacar unos versos de la Farsa del juego de cañas (ca. 1550), de Sánchez de Badajoz ${ }^{29}$ :

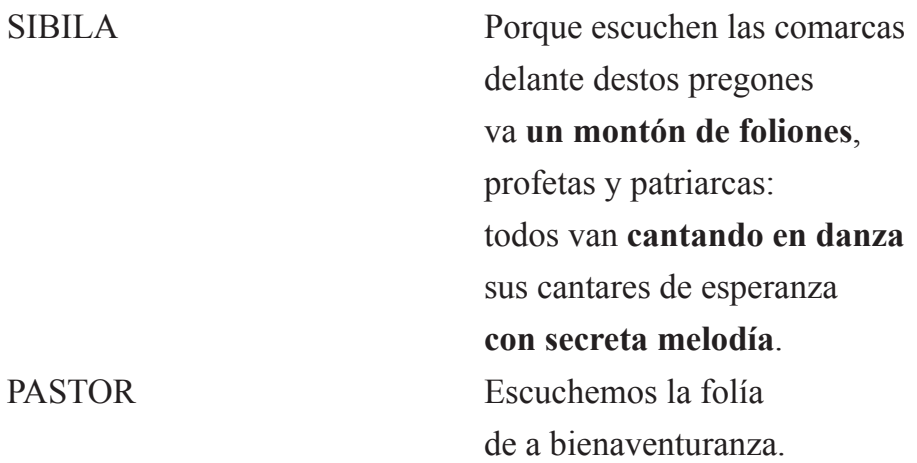

Aquí folían y cantan con sus panderetes y su atanbor los que están encubiertos en el coro, sin que nadie los vea, la folía siguiente al tono de: "¿Quién os puso en tal estado? La de lo verdugado»

Del fragmento pueden extraerse varias conclusiones. En primer lugar, el término "foliones" parece referirse a los participantes de las folías, al igual que sucedía en algunas de las crónicas citadas. Se dice que eran "un montón" — coincidiendo con las frecuentes alusiones al gran número de figuras que intervenían por lo general en las folías - y que iban "cantando en danza" - cabe suponer que cantando mientras bailaban - una "secreta melodía". Este último verso parece explicarse en la didascalia siguiente, donde se anuncia que los personajes que están en el coro sin ser vistos por el auditorio, serán quienes canten con instrumentos de percusión y con un tono concreto. Resulta también llamativa la transformación de las folías en el verbo "foliar", que parece corresponder a la acción de cantar, con acompañamiento de percusión y bailando, un tono.

Determinados entremeses y mojigangas del siglo XVII contienen asimismo alusiones a folías, que curiosamente suelen denominarse en este repertorio como foliones ${ }^{30}$, hasta el punto de que existe incluso una pieza que lleva por título El Folión (ca. 1662) ${ }^{31}$. No es casualidad que ésta fuera escrita precisamente por un dramaturgo portugués, Juan de Matos Fragoso (Alvito, Portugal, 1608 - Madrid, 1689). En efecto, al final de El Folión se interpreta el baile que aquí se denomina como "folión", pero que no parece ser sino unas folías portuguesas con su acompañamiento de sonajas y tambores característico:

\section{GRACIOSO Con el uno y otro son}

al uso de Portugal

\footnotetext{
${ }^{29}$ Weber de Kurlat, Frida, “Gil Vicente y Diego Sánchez de Badajoz... op. cit., pp. 152-153.

${ }^{30} \mathrm{Al}$ respecto véase Cotarelo y Mori, Emilio, Colección de entremeses, loas, bailes, jácaras y mojigangas desde fines del siglo XVI a mediados del XVIII, Madrid, Bailly-Baillière, 1911, p. CCXLV-CCXLVI.

${ }^{31}$ Matos Fragoso, Juan de, Folión [Manuscrito]: mojiganga, BNE, MSS/16505.
} 
el baile puede acabar.

GRACIOSA Portugal va un folión.

Toma tú aquestas sonajas, yo estotras tomarme quiero, toca el tambor, yo el pandero

Cantando y hagámonos todos rajas ${ }^{32}$.

"Si vos miña may

pelejáis conmigo

$[\ldots]$

Se repite.

Hacen una culebra y cantando todos esto con que acaba el baile.

$[\ldots]$

Como puede comprobarse, se trata de un baile cantado (en un portugués sometido a distorsión y parodia), y acompañado de instrumentos de percusión (sonajas, tambor y pandero). En estos elementos parece ajustarse bastante bien a las conclusiones extraídas tras el análisis de las relaciones localizadas.

De nuevo encontraremos el término "folión" (o "folijón") asociado a una pieza muy parecida en el Entremés del Alcalde Ardite (ca. 1640) de Francisco de Rojas Zorrilla (Toledo, 1607-Madrid, 1648) 33, y además, también convertido en verbo: "foliar" ("foliando"). Cuando los personajes ejecuten danzas del Corpus, saldrá una mujer "de portuguesa" y comenzará a entonar lo que sigue:

$\begin{array}{ll}\text { MUJER } & \text { Una pançada } \\ & \text { vos daré, si vos turbáis } \\ & \text { conmigo, que eu so honrada } \\ & \text { muller, paso miña vida } \\ \text { follijando co as sonajas } \\ \text { e para que lo cregáis } \\ \text { aqueste follijón vaya. } \\ \text { Canta } \\ \text { Ollay mi niña fermosa e graciosa, } \\ {[\ldots]}\end{array}$

Asimismo, en la mojiganga de La manzana (1668), se halla el siguiente diálogo:

ALCALDE Pues atiende, porque sale

la danza de portuguesas

con unas letras de alcorza

\footnotetext{
${ }^{32}$ Bailar sin descanso.

${ }^{33}$ Se conserva en BNE, MSS/15168-3.
} 
y unos tonos en conserva.

Sale JUNO con una danza de portuguesas ridículas, con tamboril como folión, y cantan.

PORTUGUESA“¡Ay, festejai, festejai, mininos, ay, festejai o culto divino!"

\section{$[\ldots]$}

Sirvan estos ejemplos, de los muchos que se podrían citar, para comprobar cómo la idea de un espectáculo festivo con danza, canto y percusión continúa presente, pero ahora bajo el nombre de "folión" que parece referirse a lo que antes eran las folías. En todo caso refleja la pervivencia de esta danza, que a su paso a los escenarios habría perdido su carácter urbano, pero que continuaba ligada aún a finales del siglo XVII a la identidad de lo portugués ${ }^{34}$. Constituye un ejemplo de cómo la música es un medio particularmente eficaz para (re-)crear un tiempo y definir una identidad.

\section{Conclusiones}

A través de determinadas relaciones históricas del siglo XVI, se ha podido comprobar que las folías fueron en esta centuria un espectáculo de tipo procesional, caracterizado por el baile, el ruido y la algarabía, que convirtió al espacio urbano de las principales ciudades portuguesas en un escenario provisional donde individuos de todas las clases sociales tenían cabida. Sus participantes, los denominados "foliones" o "folliães", se caracterizaban por su vistoso (y en ocasiones elaborado) vestuario y los instrumentos de percusión que tocaban. Tal fue su importancia como parte de las folías que en ocasiones se habla de la presencia de los foliones para referirse indirectamente a aquéllas, así como a los instrumentos de percusión que las identificaban. Se dice de los foliones que "andaban" por plazas y caminos entonando canciones de carácter alegre, en tal número y con tanto ruido de sonajas y tambores que era difícil entenderles. Con todo, las folías debieron ser un espectáculo agradable de ver que sin duda gozó del favor de la realeza, tal fue así que desde la segunda mitad del siglo xvi pasó a ser una danza aristocrática.

Una de las razones de su buena recepción bien pudo residir en estar ligada a la tradición portuguesa, y ser, por tanto, una práctica festiva que (re-)creaba un espacio y contribuía a construir una identidad. Esto no solo puede observarse en alguno de los testimonios citados, como aquel en el que doña María Manuela de Portugal ve y escucha en Cáceres unas folías que

\footnotetext{
${ }^{34}$ Sobre la caracterización del tipo literario del portugués en el teatro del siglo XVII (donde se analizan además las menciones a las folías), debe consultarse Borrego, Esther, "Portugal y los portugueses en el teatro cómico breve del siglo XVII: de los entremeses a los villancicos", Hipogrifo: Revista de Literatura y Cultura del Siglo de Oro, 3 , 2 (2015), pp. 49-69.
} 
le hacen "viajar" a su país ("folías que es lo que más por allí se usa por ser raya de Portugal y lo que entonces más agradaba a su Alteza y regocijaba a las damas por parecerles que aún no habían salido de su tierra"), sino también en la introducción de folías en obras teatrales de los siglos XVI y XVII para caracterizar musicalmente al personaje del portugués. 